Article

\title{
Grid-Scale BESS for Ancillary Services Provision: SoC Restoration Strategies
}

\author{
Giuliano Rancilio ${ }^{1, *(\mathbb{D}, \text { Arianna Rossi }}{ }^{1}$, Claudio Di Profio ${ }^{1}$, Martino Alborghetti ${ }^{1}$, \\ Andrea Galliani ${ }^{2}$ and Marco Merlo ${ }^{1}$ (D) \\ 1 Politecnico di Milano-Department of Energy, Piazza Leonardo Da Vinci 32, I-20133 Milano, Italy; \\ arianna.rossi@polimi.it (A.R.); claudio.diprofio@mail.polimi.it (C.D.P.); \\ martino1.alborghetti@mail.polimi.it (M.A.); marco.merlo@polimi.it (M.M.) \\ 2 Autorità di Regolazione per Energia, Reti e Ambiente (ARERA), Piazza Cavour 5, I-20121 Milano, Italy; \\ agalliani@arera.it \\ * Correspondence: giuliano.rancilio@polimi.it
}

Received: 19 May 2020; Accepted: 11 June 2020; Published: 15 June 2020

check for updates

Featured Application: Support for policymaking in electricity balancing markets.

\begin{abstract}
The future power system, characterized by lower inertia, reduced programmability and more distributed architecture, will depend on prompt and reliable control systems. Quick ancillary services provided by battery energy storage systems (BESS) could be a resource in order to deliver fast and precise response to frequency events. Degrees of freedom in the design of innovative products traded on ancillary services markets give the asset manager room for developing state-of-charge (SoC) restoration mechanisms. These are necessary to effectively exploit BESS as key resources for electricity balancing. This study compares the main SoC restoration strategies. It aims to define which ones are suitable for guaranteeing the reliability of the provision and the return on the investment. A robust regulatory framework analysis describes the degrees of freedom guaranteed by the main experiences around Europe. In this paper, a BESS model with variable efficiency is used to compare the provision of Frequency Containment Reserve (FCR) with different SoC restoration strategies exploiting one or more degrees of freedom. Here, we show that the degrees of freedom are key to the reliability of provision. Among most diffused mechanisms, dead-band strategies secure the desired consistency, but require large energy flows for SoC management. Thus, BESS life and economics decrease. The strategies based on minimum available energy guarantee assured reliability while being fair with BESS life and operation costs.
\end{abstract}

Keywords: batteries; BESS; frequency regulation; SoC restoration; ancillary services; EFR; degrees of freedom; balancing; energy storage; Fast Reserve

\section{Introduction}

As the renewable energy sources (RES) penetration level increases, frequency deviations are more frequent because of the inherent uncertainty of solar and wind sources. As RES are typically connected to the grid through a power electronic inverter, substituting the conventional power plants with power electronic inverters will decrease the inertia of the power system. Long-term renewable energy integrations studies show that the rise in renewables could call for increased levels of frequency control [1-3]. Frequency control is included in the ancillary services necessary to guarantee the quality of supply and stability in the power systems [4]. In particular, it assures the real-time balance between electricity generation and demand. Energy storage systems (ESS) are capable of providing different services to the electric grid: peak shaving, load leveling, spinning reserve, capacity firming, up to 
frequency regulation. Above all, batteries are well suited to provide balancing services and fast frequency response because of their short response times. Therefore, the share of battery energy storage systems (BESS) in the frequency regulation market is rapidly increasing [5] thanks to the rapid decrease in battery investment cost and to the increase in renewable energy generation.

Many of the utility-scale batteries around the world provide innovative ancillary services to the power system. In Alaska, the electricity utility installed a $3 \mathrm{MW} / 750 \mathrm{kWh}$ lead-acid battery system into an island system, as spinning reserve, in order to mitigate the curtailment of energy from wind farms and to provide frequency response within $0.5 \mathrm{~s}$ [6]. In this way, diesel Gensets have been limited. In Illinois, a $31.5 \mathrm{MW}$ battery storage was located near a wind farm project and solar plant to provide fast frequency response as well as other ancillary services. Similarly, Australia's energy market operator contracted Tesla's 100 MW/129 MWh lithium-ion battery in Hornsdale. This battery was considered the largest ESS when it was built and it provides frequency control and participates in the ancillary services market (ASM) [7]. In Germany, it was recognized that battery energy storage systems (BESS) can play an active role in providing fast frequency response: in 2017, BESS systems provided about $200 \mathrm{MW}$ of Frequency Containment Reserve (FCR), about 31\% of the market. In Italy, to date, only significant thermal and programmable hydroelectric plants (i.e., larger than $10 \mathrm{MVA}$ ) compulsory provide ancillary services. Recently, a general reform of dispatching services was proposed: in the meantime, several pilot projects have been defined, such as the one aimed at opening the ASM for resources not already enabled (these resources could provide ancillary services per unit or via aggregate) [8-10].

Furthermore, in order to exploit the batteries' capability to provide very quick and accurate response power, transmission system operators (TSOs) are reviewing their network codes to test and introduce innovative ancillary services also suitable for ESS. For example, in the UK, in 2016, National Grid conducted an enhanced frequency response (EFR) tender under which it contracted eight battery storage facilities for four years to provide rapid response frequency reserves with high technical requirements on response speed (within 1 sec) [11]. In 2019, the Italian TSO launched a public consultation to introduce and test fast primary frequency control regulation, named Fast Reserve service, with a response time of $1 \mathrm{~s}$ [10].

FCR in European markets must be delivered continuously during the contracted period (Article 156 of System Operation Guidelines) [12]. This is a problem for an asset featuring a limited energy reservoir (such as a battery), because when it is completely charged or discharged, it can no longer provide a symmetric service and faces penalties (that can even lead to exclusion from the market). Therefore, on the one hand, TSOs defined additional requirements specifically for assets with limited energy reservoirs to provide FCR, e.g., in Continental Europe and Nordic Synchronous Area they must be able to fully activate FCR continuously (in both positive and negative directions) for at least $15 \mathrm{~min}$ (but not exceeding $30 \mathrm{~min}$ ) [12]. This $15 \mathrm{~min}$ criterion is adopted by TSOs to cope with the greatest frequency perturbation. However, even considering the higher frequency deviation occurred in Continental Europe during the last years [13], frequency was restored in less than $8 \mathrm{~min}$. The time elapsed at a deviation equal to or greater than the one required for full activation of provision is even lower. On the other hand, TSOs identify some degrees of freedom (DoF) allowing for BESSs state-of-charge (SoC) management. In the UK, EFR regulation sets a dead-band in which BESS can be freely operated within a $\pm 9 \%$ range (the maximum export/import power must not exceed $9 \%$ of the BESS's full-scale range) [11], this way EFR allows the development of a dead-band strategy for $\mathrm{SoC}$ restoration. In addition to the dead-band, a so-called envelope provides flexibility in provision devoted to supporting SoC maintenance. In this envelope, over or under-regulation is permitted. Thus, operators can manage the battery SoC by increasing or decreasing the control power demand indicated by the power-frequency characteristic by a fraction of regulating power. So, in the case of low SoC and frequency above the nominal value, the battery can over-regulate to charge faster and get back to target SoC. In Germany, several degrees of freedom are allowed by the four German TSOs to keep the $\mathrm{SoC}$ within the permitted range [14]: in addition to the dead-band strategy, operators can manage 
the battery SoC by providing over or under-regulation up to $20 \%$ of regulating power, adjusting the gradient of the provided FCR power within certain boundaries or trading energy on the electricity market. In Italy, the UPI pilot project, which allows the use of BESSs integrated with conventional relevant units to provide FCR, is underway. During the provision of FCR, the SoC can be restored only by exchanging energy with the integrated programmable plant and not by exchanging energy with the grid [9]. In case SoC diverges, service provision must be interrupted and SoC restored. Other services foresee minimum and maximum SoC thresholds: SoC restoration must operate when SoC gets above the maximum or below the minimum. These thresholds are established based on the requirement of always guaranteeing minimum available energy to activate the service in both upward and downward directions [10].

There is not yet a homogeneous identification of the best DoF for SoC management. In literature, different SoC controllers, aimed at efficiently providing primary frequency control reserve, have been investigated. In [14], a control algorithm that includes the DoF in place in the German market was implemented. It compares the use of dead-band, the exploitation of over-regulation, the use of thresholds for permissible SoC as criteria to implement a restoration strategy. In [15], the reliability in EFR provision is improved by exploiting dead-band strategies for managing SoC. In [16], the possibility of submitting separate bids for positive and negative PCR in Denmark is studied: SoC restoration is provided by forcing battery charge when $\mathrm{SoC}$ is below a certain threshold. All these studies present a dedicated energy flow for SoC restoration. Therefore, these strategies can be defined as "active" SoC restoration. In active SoC restoration, the dedicated energy flow is usually paid by the asset operator on the electricity market in several forms (e.g., day-ahead or intraday market, imbalance discipline).

As previously mentioned, ancillary services (FCR included) are essential for the safe management of the electric system. For this reason, TSOs can ask the BSP not (or partially) correctly providing the required service to pay a penalty. The noncompliant provision of service is called nonperformance (NP) and the related economic fee is the so-called Nonperformance Penalty (NPP). Regarding FCR, NPP may consist of the deletion of the availability payment (as is, for example, in Denmark [17]) or a financial penalty higher than the availability payment (as, for example, in Italy for Fast Reserve pilot projects [10]).

For the analysis of BESS operation, a proper model has to be implemented. In literature, several models [18] with different degrees of accuracy are in place for batteries: accuracy is usually directly proportional to the computational effort. Empirical (analytical) models do not represent electrochemical processes, but empirically fit the KPIs of battery operation throughout past experimental data for estimating the future behavior of BESS [19]. This kind of model has already shown a reduction in computational effort and an acceptable accuracy in predicting battery behavior [20]. Furthermore, to simulate BESS behavior, not only battery cells but also the complementary part of the system should be considered since it has a nonnegligible impact on operational losses, as highlighted by $[21,22]$. It includes, usually, a power conversion system (PCS) and other loads providing auxiliary services (e.g., monitoring system, alarms and HVAC system). In [23], authors develop a BESS empirical model that evaluates the efficiency of the BESS from a system perspective. Finally, to properly evaluate the BESS business case, battery aging should be considered. Battery aging is related to operational conditions: as the batteries are charged and discharged there is a capacity loss in the battery. In order to evaluate this phenomenon, different indicators exist in the literature: the most used is the State-of-Health $(\mathrm{SoH})$ [24]. SoH represents a measure of BESS ability to store and deliver electrical energy, compared with a new battery. Depending on its actual application, the end of life (EoL) for a battery is reached with a SoH value between $70 \%$ and $80 \%$ [25].

In this study, different active $\mathrm{SoC}$ restoration strategies are investigated adopting the empirical BESS model, presented in [23], able to provide FCR in Italy. To estimate battery life, a SoH model was developed based on [26]. The SoH model considers both cycle aging and calendar aging in terms of capacity fade. The strategies analyzed are thoroughly developed to be as close as possible to the most innovative regulatory frameworks for BESS integration in ancillary services provision. Results 
are presented in terms of technical and economic performance. Both the perspective of the system operator and of the investor are evaluated and discussed. The rest of the article is organized as follows: Section 2 describes the proposed methodology for SoC restoration strategies, model development and the description of the case study. Section 3 presents the results of the simulations and highlights the main findings. Section 4 presents a broader discussion of the results, summarizes conclusions and takeaways and suggests foreseen future steps.

\section{Materials and Methods}

Given the pivotal need for new resources for the grid's frequency control, as detailed in the previous chapter, this study focuses on the use of a BESS numerical model to analyze FCR provision. In particular, the goal is to investigate the best option for the management of the BESS SoC. For such a goal, a reliable BESS model is required in order to provide a realistic figure; in the proposed study a runtime SoC evolution empirical model developed on experimental data by a large-scale industrial BESS [23] is adopted. It features a variable efficiency depending on the power rate and SoC.

The BESS model receives as input power setpoints requested grid side per step of the simulation. The power setpoints are updated via a lookup table that estimates the step efficiency of the system. This lookup table considers the instantaneous SoC and power requested to the battery and returns the efficiency of the system, considering PCS and battery losses. The efficiency is multiplied (charging) or divided (discharging) by the power setpoint to assess the power flowing in the battery. This power is checked against the maximum/minimum power that can be provided by a battery at that SoC. To do this, the model features a capability curve that prevents the battery from delivering high power rates at extremely high (for charging) or low (for discharging) SoC. If power requested is outside the capability of the battery, the absolute value of real power is set equal to the limit. The real power is the responsibility for the $\mathrm{SoC}$ variation in the step. The model computes $\mathrm{SoC}$ evolution each step to provide the power requested. Moreover, the model returns if the dispatching order is not (or partially)

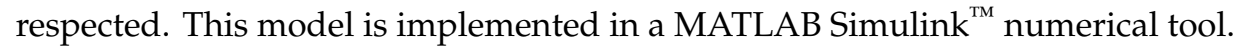

The model is fed by network frequency data from Central Europe Synchronous Area (CESA) for the year 2016 [27]. These data have a $1 \mathrm{~s}$ sampling rate and a resolution of $0.1 \mathrm{MHz}$. The FCR controller block of the Simulink ${ }^{\mathrm{TM}}$ tool transforms frequency trends in power setpoints requested to BESS via a droop control curve based on the following equation.

$$
\mathrm{D}=-\left(\mathrm{dF} / \mathrm{F}_{\mathrm{n}}\right) /\left(\mathrm{dP} / \mathrm{P}_{\mathrm{n}}\right) \times 100,
$$

where $\mathrm{D}$ is the droop value in percentage, $\mathrm{dF}$ is the frequency deviation in $\mathrm{Hz}, \mathrm{F}_{\mathrm{n}}$ is the nominal frequency of $50 \mathrm{~Hz}$, dP is the power setpoint requested for FCR in MW, $P_{n}$ is the nominal power of the BESS in MW. In this study, the convention of generators is adopted, with power injected to the grid as positive power and power absorbed as negative. In addition, the curve features a $\mathrm{dF}$ dead-band inside which $\mathrm{dP}$ requested is equal to 0 and a full activation $\mathrm{dF}$ over which the $\mathrm{dP}$ requested is equal to $P_{\mathrm{n}}$. This droop curve is an elaboration of the one in place in Italy for conventional thermal generators $[9,28]$. In the framework of the study, $\mathrm{D}=0.075 \%$. All the relevant data for the curve can be seen in Table 1 . The curve is shown in Figure 1.

Table 1. Droop curve data.

\begin{tabular}{cc}
\hline Droop Value (D) & $\mathbf{0 . 0 7 5 \%}$ \\
\hline Dead-band dF $(\mathrm{mHz})$ & \pm 20 \\
Full activation $\mathrm{dF}(\mathrm{mHz})$ & \pm 37.5 \\
\hline
\end{tabular}




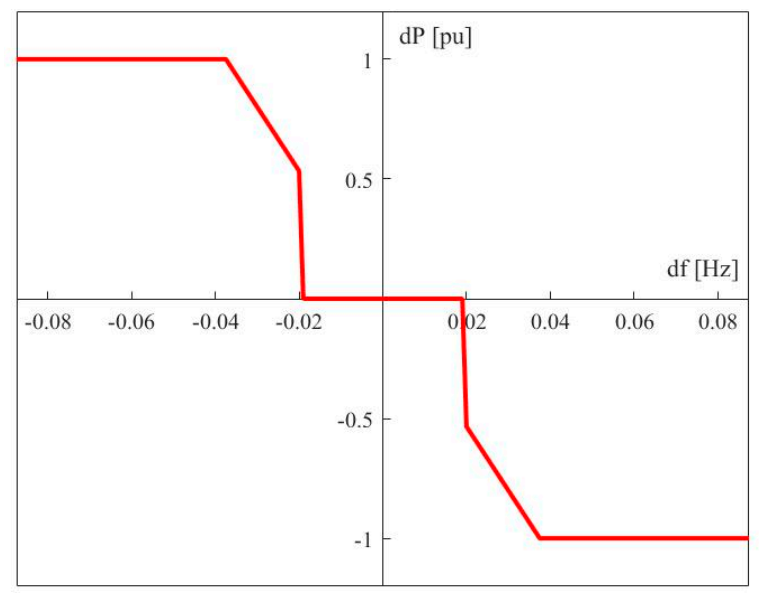

Figure 1. Droop control curve based on the Italian Grid Code implemented in the battery energy storage system (BESS) model for Frequency Containment Reserve (FCR) provision.

Besides the FCR controller, another block implements the SoC restoration strategy in the Simulink ${ }^{\mathrm{TM}}$ tool. The power requested by FCR provision $\left(\mathrm{P}_{\mathrm{FCR}}\right)$ and the one required for $\mathrm{SoC}$ restoration $\left(\mathrm{P}_{\text {rest }}\right)$ are summed up and represent the power setpoint demanded to the BESS ( $\left.\mathrm{P}_{\text {req }}\right)$.

$$
\mathrm{P}_{\text {req }}=\mathrm{P}_{\mathrm{FCR}}+\mathrm{P}_{\text {rest }}
$$

The BESS model updates the power setpoint consistently with efficiency and capability charts, and consequently updates SoC value for each second of the analyzed year. The outcomes of the model are the SoC trend, the power and energy flows requested and actually flowing in the battery, the share of energy flows for FCR provision and for SoC restoration. The simplified block diagram of the BESS model is proposed in Figure 2.

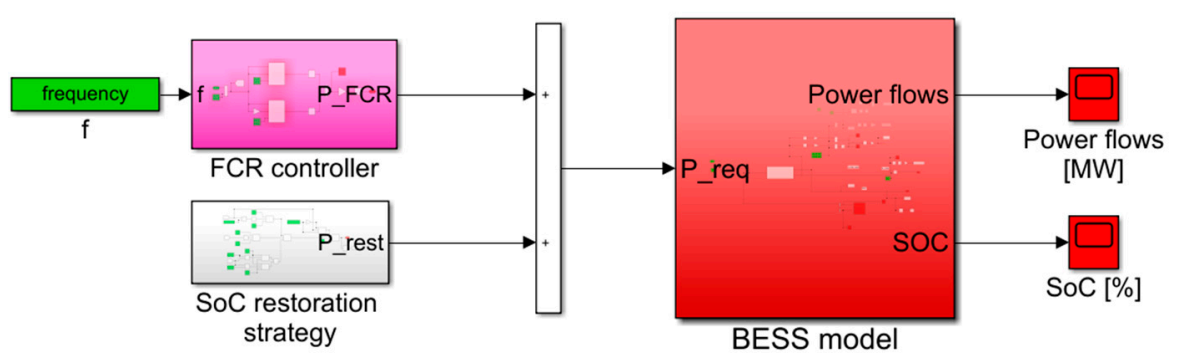

Figure 2. Simplified block diagram of the Simulink tool for the FCR provided by BESS.

A set of simulations performs the FCR provision on the same frequency trend (see Figure 3) and on the same Li-ion BESS whose main sizing data are reported in Table 2. Frequency data are from system frequency in Continental Europe Synchronous Area (CESA) for the year 2016 [27], with $1 \mathrm{~s}$ sampling rate and a resolution of $0.1 \mathrm{MHz}$.

The regulating power for FCR provision is equal to the nominal power of BESS. The difference between the simulations only relates to the SoC restoration mechanism in place. Each SoC restoration mechanism is suitable for exploiting different DoF, and therefore, it could be possibly applied in different regulatory frameworks. The SoC restoration strategies tested are listed here below and described in the following.

- The Base case implements no SoC restoration strategy.

- The No DoF case implements a SoC restoration strategy based on the interruption in service provision.

- The Over/Under-regulation case implements a SoC restoration strategy based on variable droop. 
- The Dead-band case implements a SoC restoration strategy based on dead-band strategy.

- Available energy case implements a SoC restoration strategy based on offsetting the regulating power when SoC is outside a window of acceptability.

- The Hybrid case implements a SoC restoration strategy based on offsetting the regulation when $\mathrm{SoC}$ is outside the window of acceptability and $\mathrm{dF}$ is inside dead-band.
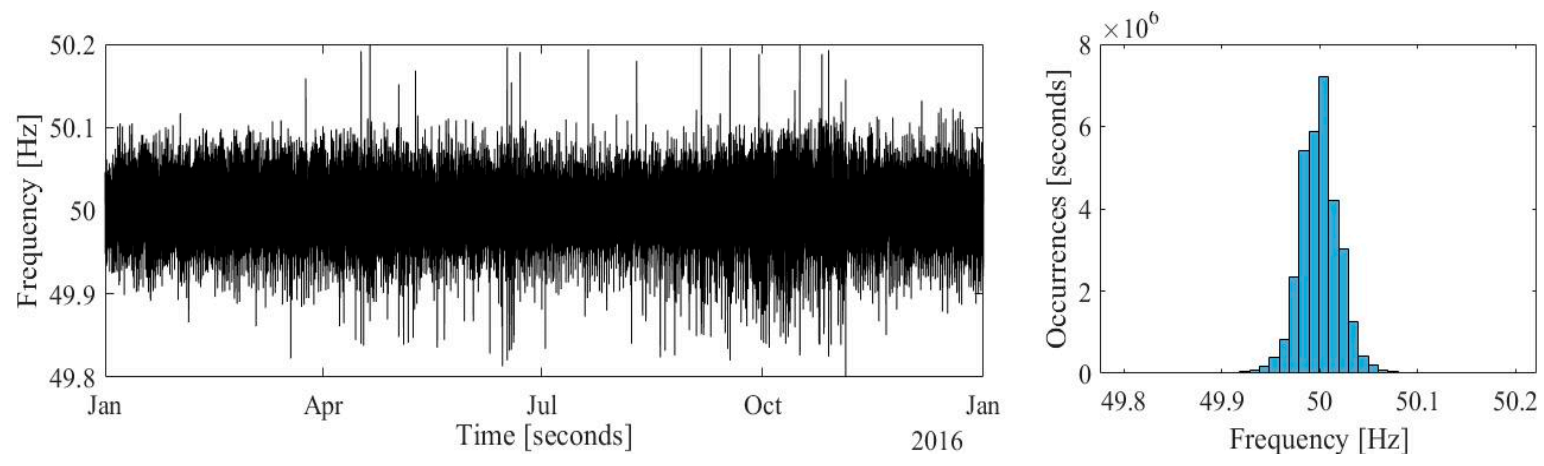

Figure 3. Yearly trend and histogram of frequency data used for simulation.

Table 2. Battery energy storage system (BESS) details for the simulations.

\begin{tabular}{ccc}
\hline Key & Abbreviation & Value \\
\hline Technology & - & Li-ion NMC \\
Nominal power $(\mathrm{MW})$ & $\mathrm{P}_{\mathrm{n}}$ & 1 \\
Nominal energy $(\mathrm{MWh})$ & $\mathrm{E}_{\mathrm{n}}$ & 2.28 \\
Energy-to-power ratio $(\mathrm{h})$ & $\mathrm{E} / \mathrm{P}$ & 2.28 \\
Maximum SoC $(\%)$ & $\mathrm{SoC}_{\max }$ & 100 \\
Minimum SoC $(\%)$ & $\mathrm{SoC}_{\min }$ & 0 \\
SoC target $(\%)$ & $\mathrm{SoC}_{\text {target }}$ & 55 \\
Air conditioning setpoint & $\mathrm{T}_{\text {in }}$ & 20 \\
temperature $\left({ }^{\circ} \mathrm{C}\right)$ & & \\
\hline
\end{tabular}

This set of active strategies presented are designed to be as coherent as possible with the ones adopted in the European experiences already mentioned. Except for the Base case, the other simulations feature a SoC restoration strategy conveniently exploiting the DoF that we assume are granted by the regulation. SoC restoration aims to bring back SoC towards a $\mathrm{SoC}_{\text {target }}$ equal to $55 \%$. $\mathrm{SoC}_{\text {target }}$ is selected based on the assumption of symmetric provision of reserves for FCR. At $\mathrm{SoC}_{\text {target}}$, energy content available (net of the efficiency) is approximately equal for upward and downward reserve.

$$
\left(\mathrm{SoC}_{\text {target }}-\mathrm{SoC}_{\min }\right) \times \eta_{\text {avg }} \cong\left(\mathrm{SoC}_{\max }-\mathrm{SoC}_{\text {target }}\right) / \eta_{\text {avg }},
$$

where $\mathrm{SoC}_{\min }$ is the minimum $\mathrm{SoC}$ of the battery, $\eta_{\text {avg }}$ is the average efficiency of the battery equal to $92 \%$ based on [23].

\subsection{Base Case}

The Base case features no SoC restoration strategy. This means that every time-frequency deviation leads the SoC towards a lower threshold (minimum SoC is $0 \%$ ), the battery can provide no more upward regulation until propitious frequency deviation (overfrequency) leads back SoC towards higher values. Vice versa, in the case of SoC approaching the upper threshold (maximum SoC is $100 \%$ ), it cannot properly provide downward regulation. 


\subsection{No DoF Case}

Conventional ancillary services barely feature DoF to the droop curve shown in Figure 1 . There is no need for conventional generators to exchange energy with the grid during the provision of the service to restore their energy content, since it is not limited. In case the regulation does not foresee any DoF, it usually inhibits the resource from the provision in the case of inadequacy (e.g., in the case of inadequacy of the available energy content). This is the No DoF case. It implements a SoC restoration that takes place when the available energy content of BESS is inadequate. Maximum and minimum thresholds are implemented on SoC: above the first (97\%) and below the latter (3\%) service is stopped and $\mathrm{SoC}$ restoration towards $\mathrm{SoC}_{\text {target }}$ begins. Power for SoC restoration $\left(\mathrm{P}_{\text {rest }}\right)$ in the No DoF case is $100 \%$ of nominal power. When $S_{0} C_{\text {target }}$ is reached, service provision restarts. All the power requested when service provision is interrupted is NP (see Figure 4).

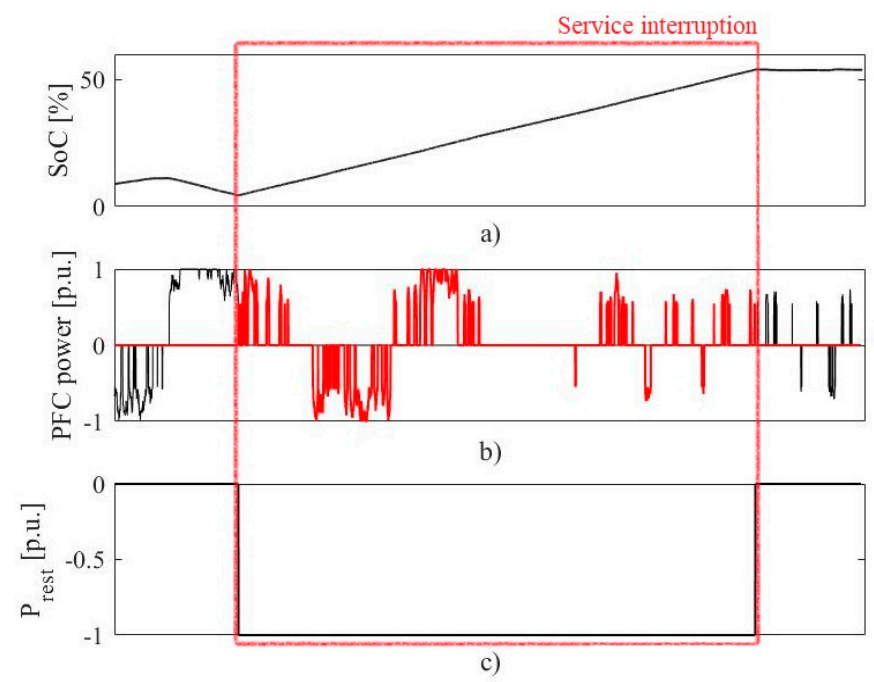

Figure 4. Schematization of state-of-charge $(\mathrm{SoC})$ restoration strategy in the No Degrees of Freedom (DoF) case, with time on the x-axis: (a) SoC evolution; (b) power requested for FCR before, during and after the service interruption; (c), restoration power. Positive power means discharge. Red trend highlights that all the power requested while service is interrupted results in nonperformance (NP) and is accounted for NPP. Power is expressed per unit with respect to the nominal power of the battery.

\subsection{Over/Under-Regulation Case}

Some innovative frequency regulation schemes allow over or under-regulation as a DoF. In such a case, $D$ is no more a single value but an interval of values $\left[D_{\min }, D_{\max }\right]$. This means that the droop curve shown in Figure 1 is modified as depicted in Figure 5. The over/under-regulation admits different $\mathrm{dP}$ for the same $\mathrm{dF}$ within the pink area. $\mathrm{dP}$ that can be applied is in the following interval.

$$
\left(\mathrm{dF} / \mathrm{F}_{\mathrm{n}}\right) \times\left(\mathrm{P}_{\mathrm{n}} / \mathrm{D}_{\max }\right) \times 100 \leq \mathrm{dP} \leq\left(\mathrm{dF} / \mathrm{F}_{\mathrm{n}}\right) \times\left(\mathrm{P}_{\mathrm{n}} / \mathrm{D}_{\min }\right) \times 100,
$$

where $\mathrm{D}_{\min }$ is $0.060 \%$ and $\mathrm{D}_{\max }$ is $0.090 \%$. The flexibility offered by the variable droop in the pink area can be exploited to restore the $\mathrm{SoC}$ without incurring in NPP. This scheme is applied, for instance, for provision of FCR in Germany [29]. 


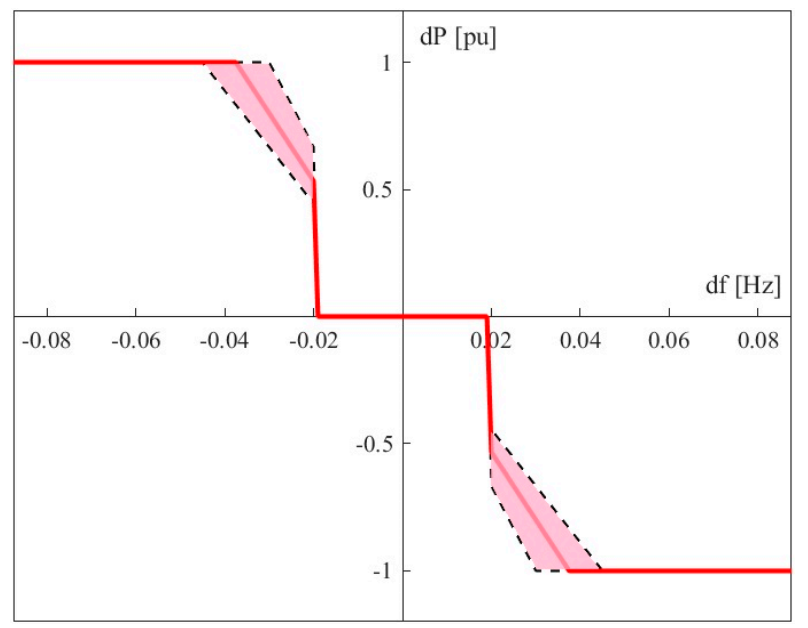

Figure 5. The variable droop adopted to simulate over/under-regulation schemes. Dead-band is equal to the one adopted in the other cases. The pink area, instead, shows the possible $\mathrm{dP}$ that can be delivered at each $\mathrm{dF}$. Full activation $\mathrm{dF}$ varies between \pm 30 and $\pm 45 \mathrm{MHz}$.

The droop value variable in time $D_{\text {var }}(t)$ adopted varies as a function of the instantaneous $\operatorname{SoC}(t)$ (Equation (5))

$$
\mathrm{D}_{\mathrm{var}}(\mathrm{t})=\mathrm{D} \times\left(1+\mathrm{R}_{\mathrm{o} / \mathrm{u}} \times\left(\mathrm{SoC}(\mathrm{t})-\mathrm{SoC}_{\text {target }}\right) / 50\right),
$$

where the over/under-regulation ratio $\mathrm{R}_{\mathrm{o} / \mathrm{u}}$ is the amount of energy that can be over/under-regulated as a percentage of regulating power: $R_{o / u}$ is $18 \%$. It is coherent with FCR in Germany (where over-regulation only is allowed) [29].

\subsection{Dead-Band Case}

When the frequency is in its dead-band, FCR does not require any dP. This circumstance is less critical for frequency control regulation in general. Thus, it is exploited in several control services $[10,30]$ to allow SoC restoration. In this case, the DoF is represented as a share of regulating power that can be offset for charging and discharging while frequency is in its dead-band. We use as offset ratio $\left(\mathrm{R}_{\text {offset }}\right)$ $25 \%$ with respect to regulating power: this is coherent with the offset allowed in the Fast Reserve pilot project in Italy. Therefore, $P_{\text {rest }}$ is computed as in Equation (6).

$$
\left\{\begin{array}{lr}
\mathrm{P}_{\text {rest }}=\operatorname{sgn}(\Delta \mathrm{Soc}) \times \mathrm{R}_{\text {offset }} \times \mathrm{P}_{\text {nom }} & \text { if }|\mathrm{dF}| \leq \mathrm{dF}_{\mathrm{DB}} \wedge|\Delta \mathrm{SoC}|>\varepsilon \\
\mathrm{P}_{\text {rest }}=0 & \text { elsewhere }
\end{array} ，\right.
$$

where sgn $\Delta \mathrm{SoC}$ is the signum function for $\Delta \mathrm{SoC}=\mathrm{SoC}(\mathrm{t})-\mathrm{SoC}_{\text {target }}$ (positive power for SoC greater than $\left.S_{\text {target }}\right), \mathrm{dF}_{\mathrm{DB}}$ is the dead-band of $20 \mathrm{MHz}$ and $\varepsilon$ is a margin of $2 \%$ to depict an acceptable margin of tolerance on $\Delta \mathrm{SoC}$. The resulting droop curve is shown in Figure 6, where the pink area represents the DoF in dead-band. 


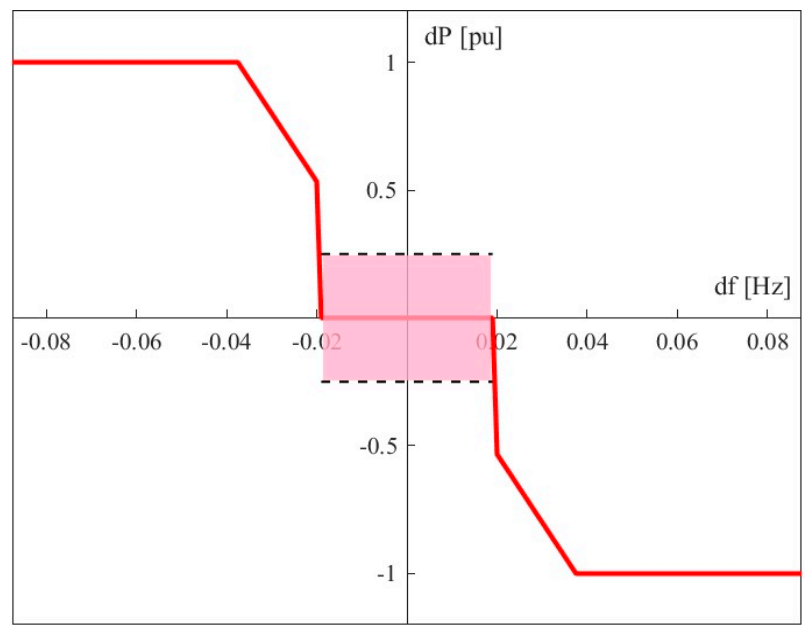

Figure 6. Droop curve for dead-band strategy, with the pink area showing the range of possible offsetting guaranteed by the DoF.

\subsection{Available Energy Case}

A further criterion for guaranteeing reliability in the case of devices with finite energy content is to require always a minimum amount of available energy. The available energy DoF implements the possibility of offsetting the delivery of service of $R_{\text {offset }}$ times the regulating power, only if the available energy content approaches the minimum threshold and until the $\mathrm{SoC}$ is restored to $\mathrm{SoC}_{\text {target }}$. In this time period, offsetting is admitted for every condition of frequency deviation. A requirement of wide use $[10,30]$ is that every device may always be available to provide $15 \mathrm{~min}$ of continuous full activation of the qualified power, both upward and downward: this is usually referred to as 15 equivalent minutes of available energy content. There is strong convergence towards this value since it relates to the contract durations for balancing products, the scheduling time for units and the imbalance settlement period in the EU [31,32]. Other regulations adopt $30 \mathrm{~min}[29,33]$. Given the steep droop curve used in this study (full activation at $37.5 \mathrm{MHz}$ of absolute deviation), a 30 min threshold is adopted. This corresponds to the given BESS (E/P of $2.28 \mathrm{~h}$ ) to the approximated SoC thresholds reported in Table 3. These thresholds take into account the effect of BESS efficiency.

Table 3. SoC thresholds for respecting the 30 min criterion.

\begin{tabular}{ccc}
\hline Threshold & Abbreviation & Value \\
\hline Higher SoC threshold & $\mathrm{SoC}_{\mathrm{hi}}$ & $85 \%$ \\
Lower SoC threshold & $\mathrm{SoC}_{\mathrm{lo}}$ & $20 \%$ \\
\hline
\end{tabular}

Therefore, in the case the $\mathrm{SoC}$ gets equal or greater than $\mathrm{SoC}_{\mathrm{hi}}$, the $\mathrm{SoC}$ restoration process is triggered and power requested to the battery $\left(\mathrm{P}_{\text {req }}\right)$ can be increased by $\mathrm{R}_{\text {offset }}$ multiplied by regulating power. This offset is kept until $\mathrm{SoC}_{\text {target }} \pm \varepsilon$ (see Table 2) is approached. On the other hand, for SoC equal to or lower than $\mathrm{SoC}_{\mathrm{lo}}$, power can be decreased to charge the battery. In this case, the offset remains until the battery reaches $S_{0} C_{\text {target }} \pm \varepsilon$. In the implementation of the algorithm, the activation of the offset depends on a flag variable whose role is shown in Equation (7) and whose use is described in Figure 7a.

$$
\begin{array}{rr}
\mathrm{P}_{\text {req }}=\mathrm{P}_{\mathrm{FCR}}+\mathrm{R}_{\text {offset }} * \mathrm{P}_{\text {nom }} & \text { if } \mathrm{SoC}(\mathrm{t}) \geq \mathrm{SoC}_{\text {target }} \wedge \text { flag }=1 \\
\mathrm{P}_{\text {req }}=\mathrm{P}_{\mathrm{FCR}}-\mathrm{R}_{\text {offset }} * \mathrm{P}_{\text {nom }} & \text { if } \mathrm{SoC}(\mathrm{t}) \leq \mathrm{SoC}_{\text {target }} \wedge \text { flag }=1 \\
\mathrm{P}_{\text {req }}=\mathrm{P}_{\mathrm{FCR}} & \text { elsewhere }
\end{array},
$$

where $P_{\text {req }}$ is the total power requested to the battery, composed by the contribution for FCR $\left(\mathrm{P}_{\mathrm{FCR}}\right)$ and the power for restoration, and flag is the flag variable. The resulting droop curve is shown in Figure $7 \mathrm{~b}$. The DoF is represented by the pink area: it can be exploited only if flag $=1$. 


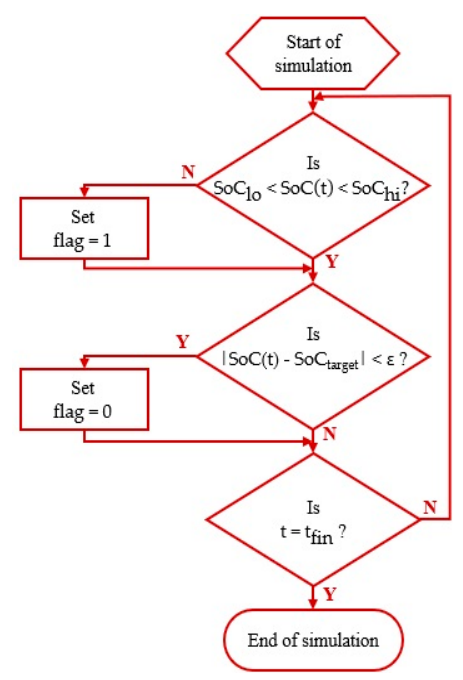

(a)

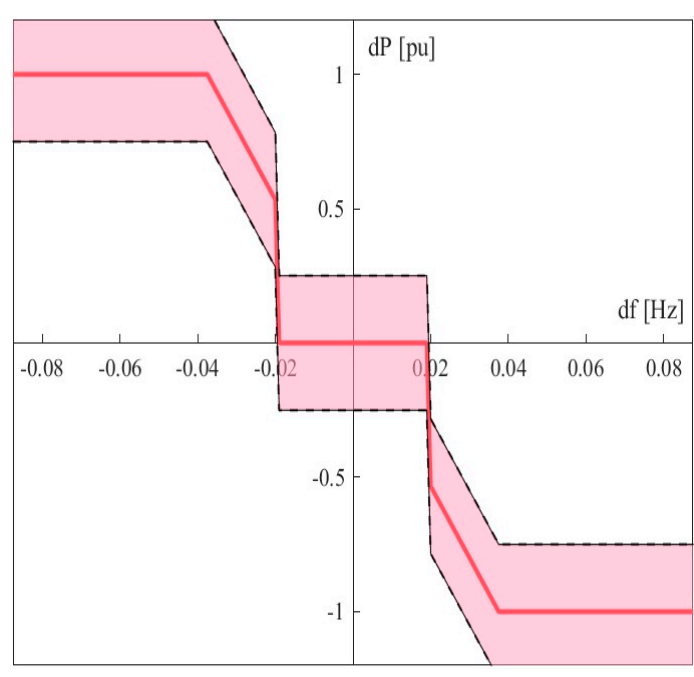

(b)

Figure 7. Schematic representation of available energy DoF case: (a) flow diagram for flag variable activation; (b) droop curve adopted. The red line is the reference droop curve without offset, to be kept while flag $=0$. The pink area delimited by the black dashed lines represents the range of power setpoints that can be adopted in the case flag $=1$. For a given $\mathrm{dF}, \mathrm{dP}$ can vertically span within the pink zone between the black dashed lines. In the simulation, this is used to restore the SoC in the case of scarce or excessive energy content.

\subsection{Double Threshold Case}

The latest active SoC restoration mechanism is a hybrid of the dead-band strategy and of the available energy strategy. The DoF that is exploited is the possibility of offsetting the $P_{\text {req }}$ while the system frequency is in its dead-band. Therefore, the flag variable is triggered when SoC gets outside the thresholds in Table 3 and stays on until SoC approaches SoC target $\pm \varepsilon$. In any case, the restoration process can only occur when the frequency is inside the dead-band expressed in Table 1. This is called the double threshold strategy. Equation (7) is reworked as Equation (8) to depict the mechanism.

$$
\begin{aligned}
& \mathrm{P}_{\text {req }}=\mathrm{P}_{\mathrm{FCR}}+\mathrm{R}_{\text {offset }} * \mathrm{P}_{\text {nom }} \quad \text { if SoC }(\mathrm{t}) \geq \mathrm{SoC}_{\text {target }} \wedge \text { flag }=1 \wedge|\mathrm{dF}| \leq \mathrm{dF}_{\mathrm{DB}} \\
& P_{\text {req }}=P_{\text {FCR }}-R_{\text {offset }} * P_{\text {nom }} \quad \text { if } \operatorname{SoC}(t) \leq \text { SoC }_{\text {target }} \wedge \text { flag }=1 \wedge|d F| \leq \mathrm{dF}_{\mathrm{DB}} \text {. } \\
& \mathrm{P}_{\text {req }}=\mathrm{P}_{\mathrm{FCR}} \quad \text { elsewhere }
\end{aligned}
$$

The resulting droop control curve with the exploitable DoF is the same as shown in Figure 6 for the dead-band strategy. The double threshold concept, thus the domain in terms of SoC and $\mathrm{dF}$ where the DoF can be exploited is described in Figure 8 . 


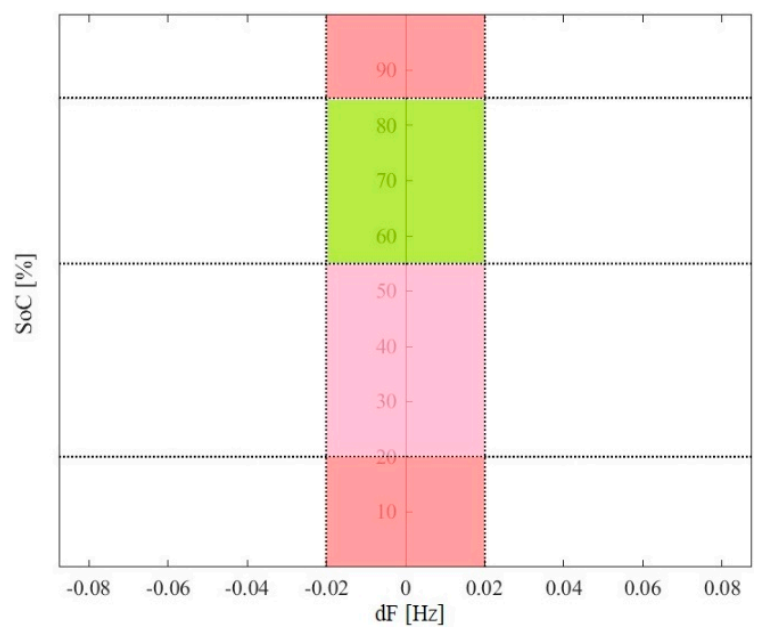

Figure 8. The double threshold domain for SoC restoration. The red area identifies the condition of $(\mathrm{dF}, \mathrm{SoC})$ for triggering the flag variable and starting SoC restoration. The pink area is where the offsetting can be exploited for charging towards $\mathrm{SoC}_{\text {target }}$. The green area shows where $\mathrm{P}_{\text {req }}$ can offset to discharge.

\subsection{Techno-Economic Analysis}

The results of the model are analyzed in terms of energy flows and associated revenue streams. The energy requested for FCR ( $\mathrm{E}_{\mathrm{FCR}}$ ) is computed as the summation of the absolute value of $\mathrm{P}_{\mathrm{FCR}}$ in time. The energy for SoC restoration is computed from $P_{\text {rest }}$ both for charge $\left(E_{c h}\right)$ and discharge $\left(E_{\text {dis }}\right)$. The energy non provided ( $\left.E_{N P}\right)$, relevant for the estimation of NPP, is computed by the model. NP occurs when the battery is not able to provide with accuracy the energy requested for the regulation. In case the error between $P_{\mathrm{FCR}}$ and the power actually delivered $\left(\mathrm{P}_{\text {del }}\right)$ by BESS overcomes $5 \%$, then all the power requested by FCR for that instant is considered as nonprovided $\left(\mathrm{P}_{\mathrm{NP}}\right)$.

$$
\begin{array}{lr}
\mathrm{P}_{\mathrm{NP}}=\mathrm{P}_{\mathrm{FCR}} & \text { if }\left|\mathrm{P}_{\text {req }}-\mathrm{P}_{\text {del }}\right| / \mathrm{P}_{\text {req }}>5 \% \\
\mathrm{P}_{\mathrm{NP}}=0 & \text { elsewhere }
\end{array},
$$

where $E_{N P}$ is the summation of the absolute values of $P_{N P}$. NP is eventually $P_{N P}$ expressed as a percentage of $\mathrm{E}_{\mathrm{FCR}}$. This index measures the reliability of the BESS as a BSP with different schemes. The cash flows related to FCR provision, to SoC restoration and to NPP are computed valorizing the energy flows with the indexes reported in Table 4, mainly referred to the Italian market, except for FCR remuneration which is referred to the German market (in $€ / M W /$ week). However, according to [34], also in Italy, FCR could be remunerated by means of availability payments in $€ / M W /$ week in the near future. The energy necessary to charge BESS for SoC restoration is valued at the yearly average purchase price in the Italian DAM, whereas the discharging energy at the yearly average positive imbalance price. NPP is valued at the average yearly marginal price in the Italian BM (to date, NPP for FCR is not defined in Italy, since FCR is mandatory). The selected parameters aim to be representative of the current situation and possible evolution in Continental Europe. 
Table 4. Economic indicators adopted in the study.

\begin{tabular}{|c|c|c|c|c|c|}
\hline Cash Flow & Name & Value & Unit & Source & Notes \\
\hline $\begin{array}{c}\text { FCR } \\
\text { remuneration }\end{array}$ & $\mathrm{R}_{\mathrm{FCR}}$ & 3310 & $€ / \mathrm{MW} /$ week & [35] & $\begin{array}{l}\text { German scheme with capacity } \\
\text { remuneration, likely to be adopted in } \\
\text { Italy. Average price (2008-2016). }\end{array}$ \\
\hline Charging cost & $\mathrm{C}_{\mathrm{ch}}$ & -53.95 & $€ / M W h$ & [36] & PUN (2017). \\
\hline $\begin{array}{l}\text { Discharging } \\
\text { remuneration }\end{array}$ & $\mathrm{R}_{\text {dis }}$ & 25.00 & $€ / \mathrm{MWh}$ & [37] & Average positive imbalance price (2017). \\
\hline NPP & NPP & -140.00 & $€ / \mathrm{MWh}$ & [37] & $\begin{array}{l}\text { For both upward and downward reserve } \\
\text { is applied a severe penalty coherent with } \\
\text { upward marginal prices on BM (2017). }\end{array}$ \\
\hline
\end{tabular}

The SoC restoration strategies allowed by the DoFs influence the return of the investment on BESS, too. To give a figure of this, the internal rate of return (IRR) for the investment at $5 \mathrm{y}$ is computed as follows.

$$
\begin{gathered}
\mathrm{NPV}=\mathrm{CAPEX}+\sum_{\mathrm{i}}^{\mathrm{N}} \frac{\mathrm{NCF}}{(1+\mathrm{IRR})^{\mathrm{i}}}+\frac{\mathrm{RV}}{(1+\mathrm{IRR})^{\mathrm{N}}}=0, \\
\text { CAPEX }=\mathrm{k}_{\mathrm{e}} \times \mathrm{E}_{\mathrm{n}}+\mathrm{k}_{\mathrm{p}} \times\left(\mathrm{P}_{\mathrm{n}}-\mathrm{E}_{\mathrm{n}}\right), \\
\mathrm{NCF}=\mathrm{R}_{\mathrm{FCR}}+\mathrm{C}_{\mathrm{ch}}+\mathrm{R}_{\mathrm{dis}}+\mathrm{NPP},
\end{gathered}
$$

where CAPEX is the cost investment for the BESS, based on the size of BESS and parameterized over $\mathrm{k}_{\mathrm{e}}=400 \mathrm{k} € / \mathrm{MWh}$ and $\mathrm{k}_{\mathrm{p}}=150 \mathrm{k€} / \mathrm{MW}$ [38]; N is the time horizon for the investment, set at $5 \mathrm{y}$; NCF is the net cash flow as the sum of the previously described revenue and cost streams (see Equation (12)); $\mathrm{RV}$ is the residual value of the asset at the end of year $\mathrm{N}$ computed as in Equation (13).

$$
\mathrm{RV}=\mathrm{CAPEX} \times\left(\mathrm{t}_{\mathrm{EoL}}-(\mathrm{N}+1)\right) / \mathrm{t}_{\mathrm{EoL}}
$$

where $t_{E o L}$ is the expected end of life (EoL) in years, hypothesizing linear RV decay with time. To estimate battery life, a SoH model was developed based on [26]. The SoH model considers both cycle aging and calendar aging in terms of capacity fade. $\mathrm{SoH}(\mathrm{EoL})$ is $80 \%$ of $\mathrm{SoH}$ at Beginning of Life (BoL): since the model estimates capacity fade, EoL energy capacity is $80 \%$ of nominal energy at BoL. The yearly capacity decay due to cycle aging $\left(\mathrm{C}_{\mathrm{cy}}\right)$ is computed as the summation of capacity decay in each step $\left(\mathrm{C}_{\mathrm{cy}}(\mathrm{t})\right)$. This is the product of the equivalent cycle (cy) and cycle decay factor $(\mathrm{cf})$ per each step $t$ of the simulation.

$$
\begin{gathered}
\mathrm{cy}(\mathrm{k})=|\operatorname{SoC}(\mathrm{t})-\mathrm{SoC}(\mathrm{k}-1)| / 2, \\
\mathrm{C}_{\mathrm{cy}}(\mathrm{k})=\mathrm{cy}(\mathrm{t}) \times \mathrm{cf}(\mathrm{t}), \\
\mathrm{C}_{\mathrm{cy}}=\sum_{\mathrm{t}}^{\mathrm{Y}} \mathrm{C}_{\mathrm{cy}}(\mathrm{t}),
\end{gathered}
$$

where $\mathrm{ff}$ is a function of the operating conditions, and in particular of c-rate at step $\mathrm{k}$ as detailed in [26]; $\mathrm{Y}$ is the number of seconds per year. Yearly calendar aging $\left(\mathrm{C}_{\mathrm{cal}}\right)$ is estimated based on capacity decay due to ambient conditions, in particular of the container indoor setpoint temperature $\mathrm{T}_{\mathrm{in}}$, as shown in Equation (17). Literature shows a clear correlation between temperature and calendar life $\left(t_{c a l}\right)$ of batteries.

$$
\mathrm{C}_{\mathrm{cal}}=1 / \mathrm{t}_{\mathrm{cal}}\left(\mathrm{T}_{\mathrm{in}}\right) \times\left(\mathrm{E}_{\mathrm{n}}-\mathrm{E}_{\mathrm{EoL}}\right) / \mathrm{E}_{\mathrm{n}}
$$

where $t_{\text {cal }}\left(T_{\text {in }}\right)$ is $16 \mathrm{y}$. This is based on [39,40], systematically reviewed in [41] for $T_{\text {in }}=20^{\circ} \mathrm{C}$, as mentioned in Table 2. The SoH is estimated summing up the yearly capacity decays as in Equation (18).

$$
\mathrm{SoH}(\mathrm{j})=1-\left(\mathrm{C}_{\mathrm{cy}}-\mathrm{C}_{\mathrm{cal}}\right) \times \mathrm{j} \text {, }
$$


where $\mathrm{j}$ is the time from the beginning of operation in years. $t_{\mathrm{EoL}}$ is obtained by dividing the total decay over life by the yearly decay as in Equation (19).

$$
\mathrm{t}_{\mathrm{EoL}}=(1-\mathrm{SoH}(\mathrm{EoL})) /(1-\mathrm{SoH}(1)),
$$

with $\mathrm{SoH}(\mathrm{EoL})=80 \%$ and $(1-\mathrm{SoH}(1))$ as the yearly variation in $\mathrm{SoH}$.

\section{Results}

As previously introduced, simulations have been performed adopting network frequency data from CESA for the year 2016 [27], with $1 \mathrm{~s}$ sampling rate and a resolution of $0.1 \mathrm{MHz}$. The economic data used come from the market prices on the DAM and on the BM for Italy and Germany (for what concerns FCR capacity remuneration). These choices have been operated for offering results that can be generalized to the whole CESA. The adoption of CESA's frequency decreases the applicability of these results to systems with less inertia and with larger frequency deviations, such as UK [42].

The model adopted is an empirical multiparameter SoC evolution model. It is obtained via an experimental campaign on an industrial BESS. Therefore, if, on the one hand, the model is accurate in representing the whole operational efficiency (also including the effect of PCS and of auxiliary systems), on the other hand, this model is validated for that device only and it could feature its peculiar behaviors. Furthermore, the possibility of an outage of the plant during the year is neglected. The adopted workstation features an Intel ${ }^{\circledR}$ Core $^{\mathrm{TM}}$ i7-10510U CPU @ $1.80 \mathrm{GHz}, 2304 \mathrm{Mhz}, 4$ Cores, 8 Logical Processors. The approximate elapsed time is $1.5 \mathrm{~h}$ per simulated year.

The results of the simulations are provided in the following. In Figure 9, the comparison of the strategies adopted can be seen.

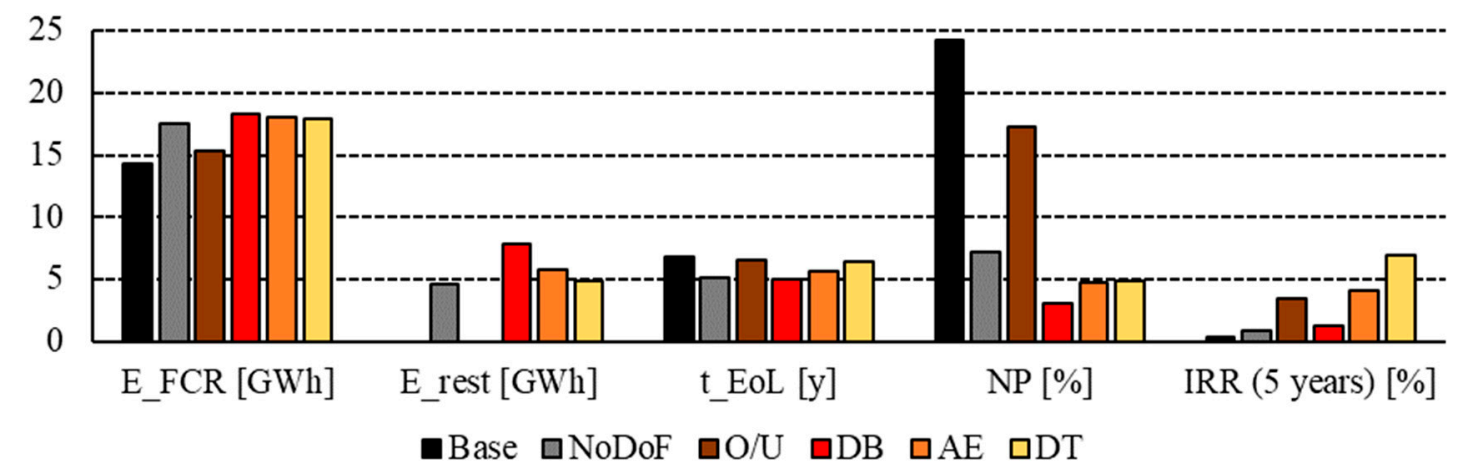

Figure 9. Summary of the results of the yearly simulations. Absolute value of energy for FCR (E_FCR), absolute value of energy for SoC restoration (E_rest), the BESS expected life (t_EoL), the ratio of NP with respect to total energy requested for FCR, the IRR at $5 \mathrm{y}$ are shown for each of the Cases: base case, no DoF case, over/under-regulation case $(\mathrm{O} / \mathrm{U})$, dead-band case $(\mathrm{DB})$, available energy case (AE) and double threshold case (DT).

Each set-up can be evaluated in terms of the provided energy for FCR: obviously, as it can be seen, this energy is larger where the NP is lower. The dead-band case (DB, in red) shows a low NP $(3.2 \%)$. Energy for SoC restoration widely varies among strategies. Base and over/under-regulation $(\mathrm{O} / \mathrm{U})$ case (in black and brown) present no energy flow for the sake of restoration, oppositely dead-band (DB) case (in red) features 7.8 GWh for restoring SoC against 18.2 GWh provided for FCR: energy flows for restoration are $43 \%$ of provided energy. In the No DoF case, the need of energy flows for restoration is lower $(27 \%)$ since SoC restoration takes place (and service provision stops) only when SoC reaches the maximum or minimum thresholds; however, the NP is significant $(7.3 \%)$ since service provision restarts only when $\mathrm{SoC}$ reaches its target value. In the other strategies, the portion of energy flown dedicated to SoC restoration varies between $27 \%$ and $32 \%$. BESS lifetime $\left(t_{\mathrm{EoL}}\right)$ estimated via the SoH model is generally very low: it ranges from $6.8 \mathrm{y}$ for the Base case to $5.0 \mathrm{y}$ for the DB case. As can be 
seen, $t_{E o L}$ is usually inversely proportional to the overall absolute value of energy flown: it is well known that limiting the equivalent cycles decreases the cycle of aging. Therefore, limiting the energy flows that do not imply a consistent revenue stream should be a target of the asset owner to preserve the BESS.

As already described, in the electricity balancing two main parties are involved: the system operator (which procures services) and the BSP (the service supplier). The two clusters of columns on the right part of Figure 9. can be investigated to evaluate the perspective of these two actors. The system operator aims to increase the reliability of provision: this is measured by NP, which must be kept as low as possible. NP below $5 \%$ can be taken as a conventional threshold to define an acceptable provision of service [10]. From this standpoint, the best result is obtained via DB (3.1\%), while the other acceptable cases are AE $(4.8 \%)$ and DT $(4.9 \%)$. With respect to the case of a standard FCR provision (Base case), $87 \%$ of nonreliability is avoided for the DB case. Furthermore, nonreliability avoided via DB is $57 \%$ with respect to a case in which no DoF are in place (case NoDoF) where the only possibility is interrupting the service provision for restoring SoC. On the other hand, the BSP is interested in the economic return on the investment. The IRR computed on a five-year business case ranged from 0.3 to $6.9 \%$. Hypothesizing a real-world discount rate around $4 \%$ for the investment in energy systems [43], the economically positive cases are AE (4.1\%) and DT (6.9\%). In any case, these feature an IRR slightly lower than hurdle rates adopted in generation companies [44]. Dead-band strategy, given the large amount of SoC restoration energy involved, is much less economically attractive for BSPs, with IRR equal to $1.2 \%$.

Figure 10 shows the SoC probability distribution for active strategies. Distribution of SoC has proven important for guaranteeing reliability and the effective use of BESS [45]. The comparison is useful to understand how effective a strategy for restoring SoC. An effective control strategy would prevent the battery from SoC saturation (at $0 \%$ or $100 \%$ ) and keep SoC close to $\mathrm{SoC}_{\text {target. }}$. Therefore, the histogram of an effective strategy should feature higher probabilities for SoC around $50-55 \%$, and much lower probabilities for SoC largely diverging from $50 \%$. This is achieved by all but Base and $\mathrm{O} / \mathrm{U}$ cases (in black and brown). On the other hand, a too stressful SoC restoration strategy would prevent the battery from being effectively exploited, by keeping $\mathrm{SoC}$ always close to $\mathrm{SoC}_{\text {target }}$. This is the case of the dead-band strategy (in red), featuring more than half of the year between $50 \%$ and $60 \%$ of SoC. 


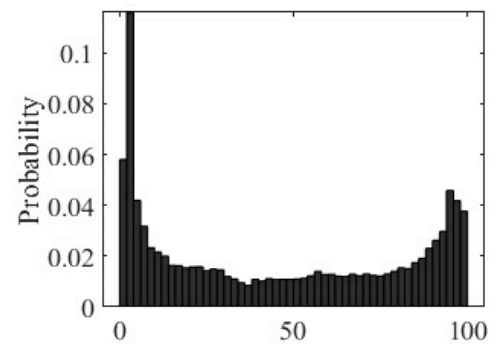

(a)

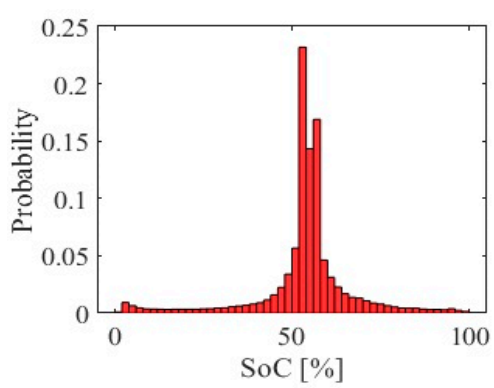

(d)

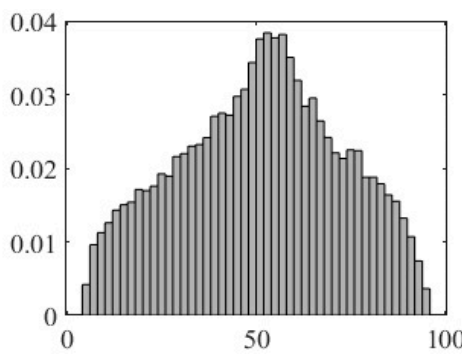

(b)

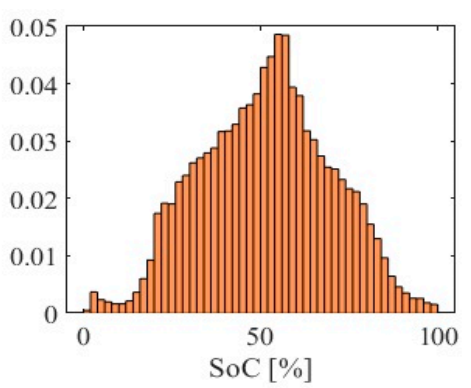

(e)

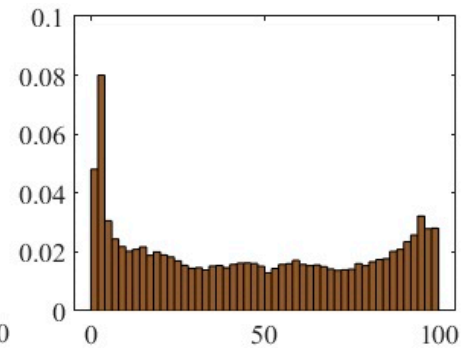

(c)

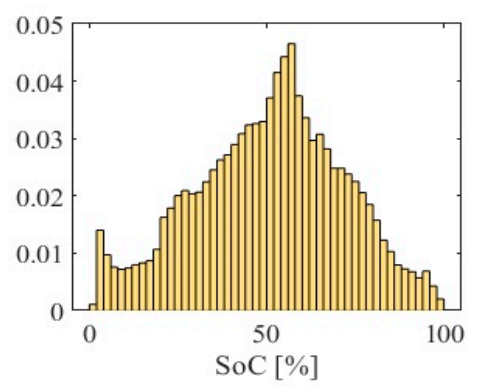

(f)

Figure 10. SoC distribution during the yearly simulation for the active SoC restoration strategies studied: (a) Base case; (b) No DoF case; (c) O/U case; (d) DB case; (e) AE case; (f) DT case. Y-axis represents the fraction of time in the year in which $\mathrm{SoC}$ is at a particular level.

\section{Discussion}

This study carefully analyzed the exploitation of battery energy storage systems to provide frequency regulation. The evolution of the power system requires reliable and rapid control of frequency deviation. BESS can provide very quick ancillary services; however, their limited energy reservoir must be taken into account when providing these services. This can be done by defining innovative requirements that implement degrees of freedom for SoC management. These DoF are used by the asset manager as a room to develop a control strategy able to restore battery SoC towards the target value. An effective $\mathrm{SoC}$ restoration strategy guarantees the reliability of provision while limiting its cost. Nonperformance is measured: the lower NP is the higher is the reliability of provision. The cost of restoration is assessed in terms of the costs of the energy flows for managing SoC and the decrease in BESS life associated with larger energy flow. Some DoF has shown effectiveness in decreasing NP while keeping acceptable IRR.

Energy flows related to SoC restoration are not negligible, ranging from $25 \%$ to $45 \%$ of the energy dedicated to services provision. They must be included in the assessment while evaluating the design of an innovative product traded on balancing markets. This paper can support NRAs, market and system operators in selecting the appropriate DoF for each product. This could lead to a suitable framework both for guaranteeing accurate respect of dispatching orders and for having a positive return on investment.

The comparison among SoC restoration strategies showed that both strategies based on dead-band (DB) and on minimum guaranteed available energy (AE and DT) are able to decrease NP below acceptable values. Instead, the absence of DoF obliges the BESS operator to interrupt the provision of the service, thus leading to higher NP. The possibility of providing over or under-regulation to manage SoC, as implemented nowadays in some EU experiences, does not prevent SoC to saturate often leading to very high NP. Among acceptable strategies, DB is hard to show a positive rate of return, due to high SoC management costs and shortened battery life. Mechanisms that offer larger DoF, such as AE and DT, present IRR greater than $4 \%$. 
Still, investment in batteries presents a return below the hurdle rates. Further works could investigate the possibility of provision of multiple services simultaneously (also including innovative ancillary service, such as very quick primary frequency regulation, which may be useful in the future power system with low inertia), to provide both SoC management and revenue stacking [46].

This is the case of "passive" SoC restoration strategies, that take advantage of the provision of further service to manage SoC. This can provide reliability of the system and largely decrease restoration costs. A study in this direction could investigate if any of the market or grid rules represent a barrier for BESS [47-49]. For instance, some issues arise when it comes to measuring, monitoring and valorizing the simultaneous provision of multiple services. Some other obstacles can be represented by a feature of market products, such as minimum bid size, distance from market closure to delivery time, symmetry and time definition of products. Furthermore, it could show if there is any way of providing a return on an investment in BESS by participation in the market only, so that no other forms of remuneration must be put in place by the system to benefit from the fast and precise regulation of BESS.

Author Contributions: Conceptualization, C.D.P., M.A. and M.M.; methodology, M.A., C.D.P. and M.M.; software, C.D.P. and M.A.; validation, M.M. and G.R.; data curation, A.R. and G.R.; writing-original draft preparation, G.R. and A.R.; writing - review and editing, A.G. and M.M.; visualization, G.R. and A.R.; supervision, M.M. All authors have read and agreed to the published version of the manuscript.

Funding: This research received no external funding.

Acknowledgments: Giuliano Rancilio is partially funded in his research activities by the Enel Foundation. The opinions reported in this paper are expressed by the Author at personal level and they do not necessarily represent the position of the Italian Regulatory Authority.

Conflicts of Interest: The authors declare no conflict of interest.

\section{References}

1. Lee, T. Energy Storage in PJM: Exploring Frequency Regulation Market Transformation; Kleinman Center for Energy Policy: Philadelphia, PA, USA, 2017.

2. Obaid, Z.A.; Cipcigan, L.M.; Abrahim, L.; Muhssin, M.T. Frequency control of future power systems: Reviewing and evaluating challenges and new control methods. J. Mod. Power Syst. Clean Energy 2019, 7, 9-25. [CrossRef]

3. National Grid ESO. Operability Strategy Report; National Grid ESO: London, UK, 2019.

4. Rebours, Y.G.; Kirschen, D.S.; Trotignon, M.; Rossignol, S. A survey of frequency and voltage control ancillary services-Part I: Technical features. IEEE Trans. Power Syst. 2007, 22, 350-357. [CrossRef]

5. IRENA. Electricity Storage and Renewables: Costs and Markets to 2030; International Renewable Energy Agency: Abu Dhabi, UAE, 2017.

6. Shamim, N.; Subburaj, A.S.; Bayne, S.B. Renewable energy based grid connected battery projects around the world-An overview. J. Energy Power Eng. 2019, 13, 1-23.

7. Hornsdale Power Reserve. Hornsdale Power Reserve. Available online: https://hornsdalepowerreserve.com. $\mathrm{au} /$ (accessed on 30 April 2020).

8. ARERA. Delibera 05 Maggio 2017-300/2017/R/eel; ARERA: Milan, Italy, 2017.

9. Terna. Allegato Tecnico UPI; Terna: Rome, Italy, 2018.

10. Terna. Accompanying Note on Fast Reserve Public Consultation; Terna: Rome, Italy, 2019.

11. National Grid. Enhanced Frequency Response-Invitation to Tender for Pre-qualified Parties; National Grid: London, UK, 2016.

12. European Commission. Commission Regulation (EU) 2017/1485; European Commission: Brussels, Belgium, 2017.

13. ENTSO-E. Continental Europe Significant Frequency Deviations-January 2019; ENTSO-E: Brussels, Belgium, 2019.

14. Zeh, A.; Müller, M.; Naumann, M.; Hesse, H.; Jossen, A.; Witzmann, R. Fundamentals of using battery energy storage systems to provide primary control reserves in Germany. Batteries 2016, 2, 29. [CrossRef] 
15. Gundogdu, B.; Gladwin, D.T.; Stone, D.A. Battery SOC management strategy for enhanced frequency response and day-ahead energy scheduling of BESS for energy arbitrage. In Proceedings of the IECON 2017-43rd Annual Conference of the IEEE Industrial Electronics Society, Beijing, China, 29 October-1 November 2017; pp. 7635-7640. [CrossRef]

16. Swierczynski, M.; Stroe, D.; Stan, A.; Teodorescu, R.; Lærke, R.; Kjær, P.C. Field tests experience from $1.6 \mathrm{MW} / 400 \mathrm{kWh}$ Li-ion battery energy storage system providing primary frequency regulation service. In Proceedings of the IEEE PES ISGT Europe 2013, Lyngby, Denmark, 6-9 October 2013; pp. 1-5. [CrossRef]

17. Merino, J.; Gomez, I.; Turienzo, E.; Madina, C.; Cobelo, I.; Morch, A.; Saele, H.; Verpoorten, K.; R. Puente, E.; Haninnen, S.; et al. Ancillary Service Provision by RES and DSM Connected at Distribution Level the Future Power System-Technical Report No. D1.1; SmartNet Project: Bizkaia, Spain, 2016.

18. Mousavi, G.S.M.; Nikdel, M. Various battery models for various simulation studies and applications. Renew. Sustain. Energy Rev. 2014, 32, 477-485. [CrossRef]

19. Ramadesigan, V.; Northrop, P.W.C.; De, S.; Santhanagopalan, S.; Braatz, R.D.; Subramanian, V.R. Modeling and simulation of lithium-ion batteries from a systems engineering perspective. J. Electrochem. Soc. 2012, 159, R31-R45. [CrossRef]

20. Iurilli, P.; Brivio, C.; Merlo, M. SoC management strategies in Battery Energy Storage System providing Primary Control Reserve. Sustain. Energy Grids Netw. 2019, 19, 100230. [CrossRef]

21. Gatta, F.M.; Geri, A.; Lauria, S.; Maccioni, M.; Palone, F. Battery energy storage efficiency calculation including auxiliary losses: Technology comparison and operating strategies. In Proceedings of the 2015 IEEE Eindhoven PowerTech, Eindhoven, The Netherlands, 29 June-2 July 2015; pp. 1-6. [CrossRef]

22. Panagiotou, K.; Klumpner, C.; Sumner, M. The effect of including power converter losses when modelling energy storage systems: A UK domestic study. In Proceedings of the 2016 18th European Conference on Power Electronics and Applications (EPE'16 ECCE Europe), Karlsruhe, Germany, 5-9 September 2016; pp. 1-10. [CrossRef]

23. Rancilio, G.; Lucas, A.; Kotsakis, E.; Fulli, G.; Merlo, M.; Delfanti, M.; Masera, M. Modeling a large-scale battery energy storage system for power grid application analysis. Energies 2019, 12, 3312. [CrossRef]

24. Lin, C.; Tang, A.; Wang, W. A review of SOH estimation methods in lithium-ion batteries for electric vehicle applications. Energy Procedia 2015, 75, 1920-1925. [CrossRef]

25. Casals, L.C.; Rodríguez, M.; Corchero, C.; Carrillo, R.E. Evaluation of the end-of-life of electric vehicle batteries according to the state-of-health. World Electr. Veh. J. 2019, 10, 63. [CrossRef]

26. Moncecchi, M.; Brivio, C.; Mandelli, S.; Merlo, M. Battery energy storage systems in microgrids: Modeling and design criteria. Energies 2020, 13, 2006. [CrossRef]

27. 50Hertz Transmission GmbH Always Up-to-Date: Our Grid Data. Available online: https://www.50hertz. com/en/Transparency/GridData (accessed on 31 October 2017).

28. Terna. Codice di Trasmissione Dispacciamento, Sviluppo e Sicurezza Della Rete; Terna: Rome, Italy, 2015.

29. Thien, T.; Schweer, D.; vom Stein, D.; Moser, A.; Sauer, D.U. Real-world operating strategy and sensitivity analysis of frequency containment reserve provision with battery energy storage systems in the german market. J. Energy Storage 2017. [CrossRef]

30. Greenwood, D.M.; Lim, K.Y.; Patsios, C.; Lyons, P.F.; Lim, Y.S.; Taylor, P.C. Frequency response services designed for energy storage. Appl. Energy 2017. [CrossRef]

31. Märkle-Huß, J.; Feuerriegel, S.; Neumann, D. Contract durations in the electricity market: Causal impact of 15 min trading on the EPEX SPOT market. Energy Econ. 2018, 69, 367-378. [CrossRef]

32. van der Veen, R.A.C.; Hakvoort, R.A. The electricity balancing market: Exploring the design challenge. Util. Policy 2016, 43, 186-194. [CrossRef]

33. Terna. Regolamento per la Fornitura del Servizio di Regolazione Primaria della Frequenza per il Tramite di Unità di Produzione Integrate con Sistemi di Accumulo; Terna: Rome, Italy, 2018.

34. ARERA. Consultazione 23 Luglio 2019-322/2019/R/eel; ARERA: Milan, Italy, 2019.

35. Fleer, J.; Zurmühlen, S.; Meyer, J.; Badeda, J.; Stenzel, P.; Hake, J.F.; Uwe Sauer, D. Price development and the bidding strategies for battery energy storage systems on the primary control reserve market. Energy Procedia 2017, 135, 143-157. [CrossRef]

36. Gestore Mercati Energetici. Relazione Annuale; Gestore Mercati Energetici: Rome, Italy, 2017.

37. Terna. Rapporto mensile sul Sistema Elettrico-Dicembre 2017; Terna: Rome, Italy, 2018. 
38. Delfanti, M.; Bovera, F.; Falabretti, D.; Merlo, M.; Rancilio, G. BESS located in Primary Substation for RES integration and ancillary services provision. In Proceedings of the 25th International Conference on Electricity Distribution, Madrid, Spain, 3-6 June 2019.

39. Schmitt, J.; Maheshwari, A.; Heck, M.; Lux, S.; Vetter, M. Impedance change and capacity fade of lithium nickel manganese cobalt oxide-based batteries during calendar aging. J. Power Sources 2017, 353, 183-194. [CrossRef]

40. Keil, P.; Schuster, S.F.; Wilhelm, J.; Travi, J.; Hauser, A.; Karl, R.C.; Jossen, A. Calendar aging of lithium-ion batteries. J. Electrochem. Soc. 2016, 163, A1872-A1880. [CrossRef]

41. Dubarry, M.; Qin, N.; Brooker, P. Calendar aging of commercial Li-ion cells of different chemistries-A review. Curr. Opin. Electrochem. 2018. [CrossRef]

42. Canevese, S.; Cirio, D.; Gatti, A.; Rapizza, M.; Micolano, E.; Pellegrino, L. Simulation of enhanced frequency response by battery storage systems: The UK versus the continental europe system. In Proceedings of the 2017 IEEE International Conference on Environment and Electrical Engineering and 2017 IEEE Industrial and Commercial Power Systems Europe (EEEIC/I CPS Europe), Milan, Italy, 6-9 June 2017; pp. 1-6. [CrossRef]

43. García-Gusano, D.; Espegren, K.; Lind, A.; Kirkengen, M. The role of the discount rates in energy systems optimisation models. Renew. Sustain. Energy Rev. 2016, 59, 56-72. [CrossRef]

44. NERA. Electricity Generation Costs and Hurdle Rates-Lot 1: Hurdle Rates update for Generation Technologies; NERA: London, UK, 2015.

45. Hesse, H.; Schimpe, M.; Kucevic, D.; Jossen, A. Lithium-Ion battery storage for the grid-A review of stationary battery storage system design tailored for applications in modern power grids. Energies 2017, 10, 2107. [CrossRef]

46. Namor, E.; Sossan, F.; Cherkaoui, R.; Paolone, M. Control of battery storage systems for the simultaneous provision of multiple services. IEEE Trans. Smart Grid 2019, 10, 2799-2808. [CrossRef]

47. Borne, O.; Korte, K.; Perez, Y.; Petit, M.; Purkus, A. Barriers to entry in frequency-regulation services markets: Review of the status quo and options for improvements. Renew. Sustain. Energy Rev. 2018, 81, 605-614. [CrossRef]

48. Poplavskaya, K.; De Vries, L. Distributed energy resources and the organized balancing market: A symbiosis yet? Case of three European balancing markets. Energy Policy 2019, 126, 264-276. [CrossRef]

49. European Commission. Study on Energy Storage-Contribution to the Security of the Electricity Supply in Europe; European Commission: Luxembourg, 2020. 